\title{
DIAPHRAGMATIC RUPTURE IN A BOY FOLLOWING BLUNT ABDOMINAL TRAUMA-A CASE REPORT
}

\author{
M A MUSHFIQUR RAHMAN ${ }^{1}$, MD. AKBAR HUSAIN BHUIYAN² ${ }^{2}$ MD. MINHAJUDDIN SAJID ${ }^{1}$, MD. \\ ABDULLAH AL FAROOQ ${ }^{1}$, MD. KHURSHID ALAM SARWAR ${ }^{1}$, TANVIR KABIR CHOWDHURY ${ }^{3}$
}

\begin{abstract}
Traumatic rupture of the diaphragm is rarely observed in children with thoracoabdominal trauma. Although dyspnea is the commonest symptom, early diagnosis is difficult as chest radiography can diagnose only half of the cases. Prompt diagnosis and surgical repair is life saving. Patient may suffer from multiple associated injuries which is often fatal. A 8 years old boy was admitted with severe respiratory distress and restlessness follwing a history of landslide few hours back. He was pale, cyanosed with hypotension, tachycardia and sweating. Bruise noted over left upper abdomen and left lower chest wall. Surgical emphysema and restricted movement during respiration was noted in the left chest wall with absent breath sound. Abdomen was scaphoid having normal bowel sound. Resuscitation was started and insertion of left intercostal chest drain tube had failed to relieve respiratory distress. A portable chest radiograph showed the chest drain tube in abdomen with mediastinal shifting to opposite side and collapsed lung margin. Left dome of the diaphragm was not clearly visualized. Re institution of chest tube was planned for immediate relief and on withdrawal of the previous drain tube dragged the omentum with it. Then the diagnosis
\end{abstract}

1. Dr. M A Mushfiqur Rahman, FCPS, MS; Dr. Md. Minhajuddin Sajid, MS; Dr. Md. Abdullah Al Farooq, FCPS, MS; Dr. Md. Khurshid Alam Sarwar, MS; Assistant Professor, Department of Pediatric Surgery, Chittagong Medical College \& Hospital, Chittagong, Bangladesh.

2. Dr. Md. Akbar Husain Bhuiyan, MS, Associate Professor, Department of Pediatric Surgery, Chittagong Medical College \& Hospital, Chittagong, Bangladesh.

3. Dr. Tanvir Kabir Chowdhury, MBBS, Post graduate student, Department of Pediatric Surgery, Chittagong Medical College, Chittagong, Bangladesh.

Correspondence to: Dr. M A Mushfiqur Rahman, Assistant Professor, Department of Pediatric Surgery, Chittagong Medical College and Hospital, W-11B, Chittagong, Bangladesh. Cell- 08801715-050512. Mail-farooq71bd@yahoo.com of diaphragmatic rupture was obvious. Laparotomy showed extensive tear of left hemidiaphragm with herniation of abdominal contents. Left costal margin was also torn but abdominal viscera were found intact. Repair was done with interrupted unabsorbable suture after keeping a chest drain tube. Post operatively the patient was kept in ward with adequate analgesia. Check $X$-ray on $1^{\text {st }}$ post operative day, showed well expanded left lung. The patient had recovered well. Drain was removed on $3^{\text {rd }}$ postoperative day and was discharged on $7^{\text {th }}$ post operative day. High index of suspicion is needed for correct diagnosis. Outcome is satisfactory if treated in time without any associated injury.

Key words: Blunt trauma, Diaphragmatic rupture.

\section{Introduction}

Traumatic rupture of the diaphragm is infrequently observed $^{1,2}$. The incidence of diaphragmatic injuries is $2.6 \%$ who had sustained thoracoabdominal trauma ${ }^{3}$. Diagnosis of acute diaphragmatic rupture is challenging even for the most experienced surgeon ${ }^{4}$. Early detection and surgical repair is vital for saving life of symptomatic children ${ }^{5}$. Left hemidiaphragm is commonly affected ${ }^{5}$. The bowel and the stomach may herniate into the thorax displacing the lung ${ }^{6}$. The mechanism is high speed blunt abdominal trauma with a closed glottis ${ }^{6}$. Massive compressive force to abdomen leads to a sudden rise of intrabdominal pressure thus breaching the weakest part of the abdominal wallthe diaphragm ${ }^{7}$. The most frequent symptom following acute rupture of the diaphragm is dyspnea, vomiting and abdominal pain ${ }^{5}$. Bowel sound may be heard in the chest ${ }^{6}$. Chest radiograph is diagnostic in more than half of the patients ${ }^{2}$. Associated injuries 
should be expected. Direct suture repair through an abdominal incision is indicated though there are recent reports of laparoscopic repair 8,9 .

\section{Case report}

A boy of 8 years old weighing $20 \mathrm{Kg}$ with a history of land slide just after taking a heavy meal got admitted in our ward with severe respiratory distress, restlessness and pallor. On examination, the patient was pale with excessive sweating, and cyanosis. His pulse rate was $124 / \mathrm{min}$. and blood pressure 100/60 $\mathrm{mm}(\mathrm{Hg})$. Systemic examination revealed bruise over left upper abdomen and left lower chest wall. Surgical emphysema was noted in left lower chest wall, part of left upper abdomen with puffy face. Movement of left hemithorax was restricted during respiration with inaudible breath sound on that side. Abdomen was not distended rather scaphoid having normal bowel sound. Attempt of resuscitation was made with the patient in propped up position, oxygen inhalation, intravenous fluid and blood transfusion with simultaneous introduction of left sided intercostal chest drain tube as we thougt it is a case of left sided hemopneumothorax. No nasogastric tube was introduced. In spite of all available efforts the patient's respiratory distress did not improve. There was 150 $\mathrm{ml}$ of serosanguinous collection through the chest drain tube but air column did not move during respiration as expected. A portable chest radiograph showed the chest drain tube in abdomen with mediastinal shifting to opposite side and collapsed lung margin. Left dome of the diaphragm was not clearly visualized (Figure-1). Re institution of chest tube was planned for immediate relief and on withdrawal of the previous drain tube dragged the omentum with it. So the diagnosis of left sided diaphragmatic rupture was obvious. Laparotomy was carried by left subcostal incision. Diaphragmatic rupture was found extending from left crus of the diaphragm up to anterior chest wall involving both muscular and tendinous part in a ' $T$ ' shaped fashion (Figure-2). Left costal margin was also torn. Whole of the stomach, a length of the small gut, transverse colon with spleen and part of left lobe of liver were found herniated into left hemithorax. Left lung was collapsed. About $100 \mathrm{ml}$ blood was sucked out from peritoneal cavity but other viscera were found intact. Repair was done with interrupted prolene suture
(Figure-3) after keeping a chest drain tube. The patient was kept in ward without ventilatory support with adequate analgesia. The patient's recovery was uneventful. Chest physiotherapy was given. Chest Xray was done on first post operative day that showed well expanded left lung, normal elevation of the left dome of the diaphragm and return of the mediastinum to normal position (Figure-4). Drain was removed on $3^{\text {rd }}$ postoperative day. The patient recovered well and was discharged on $7^{\text {th }}$ post operative day.

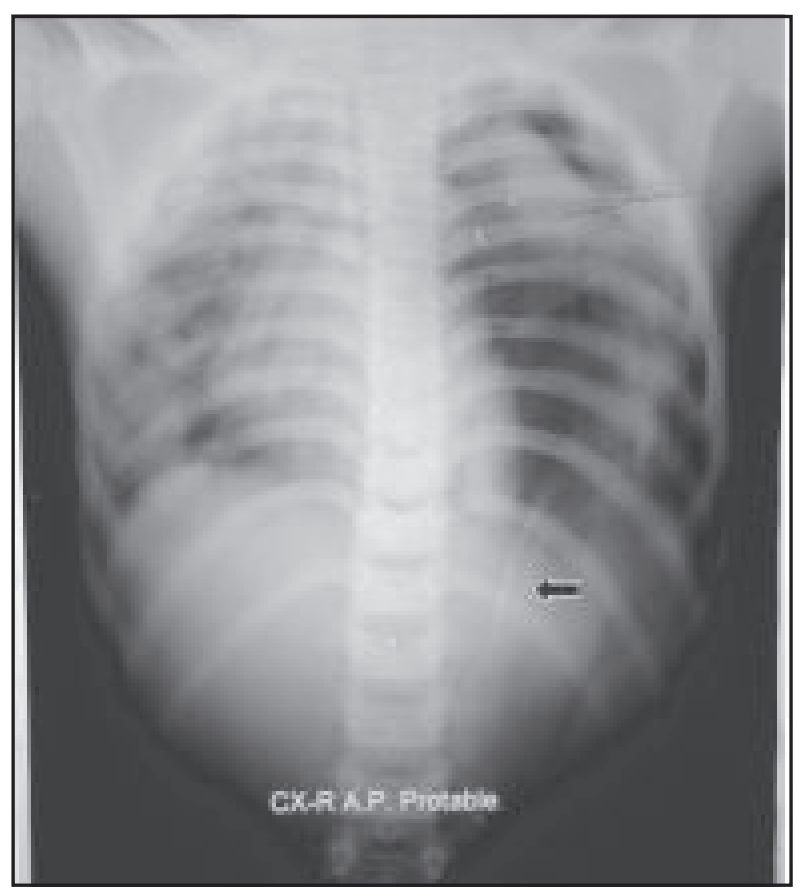

Fig.-1: Arrow showing chest drain tube in abdomen.

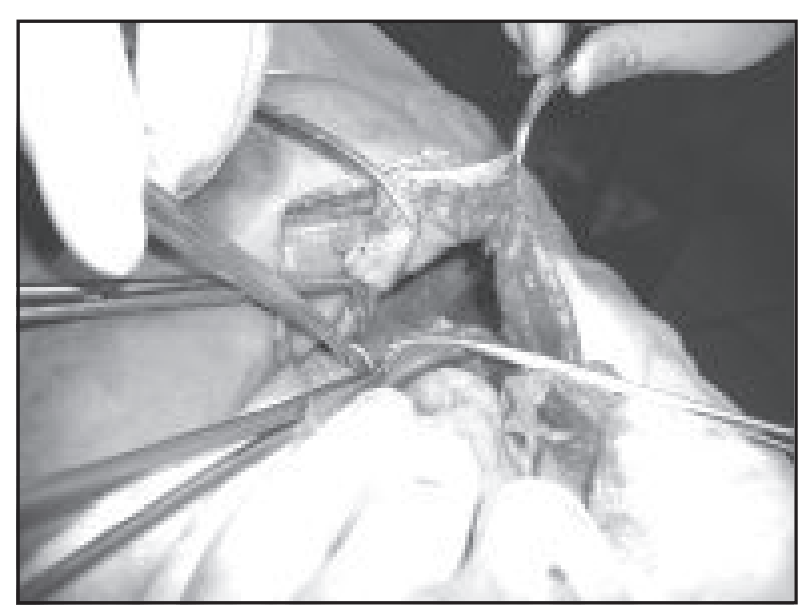

Fig.-2: Laparotomy showing left sided diaphragmatic rupture (asterix- torn diaphragmatic margin, arrowhead-collapsed lung). 


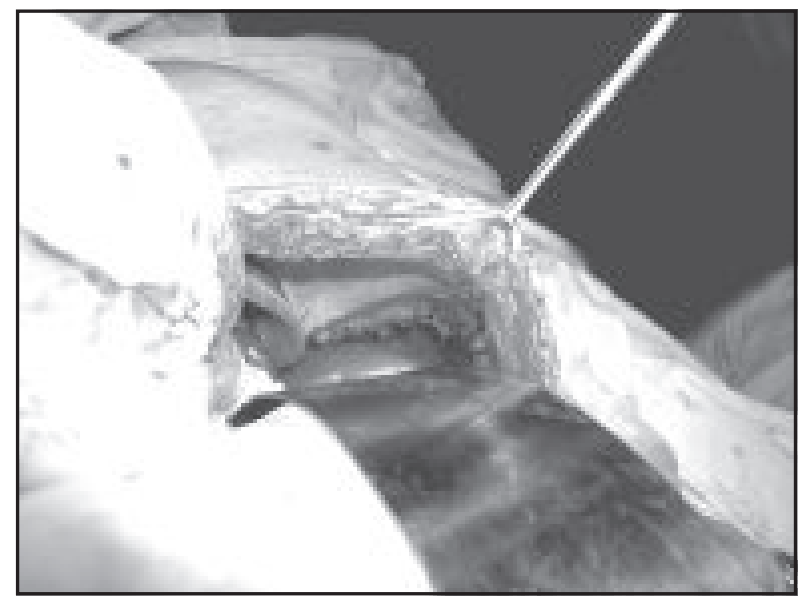

Fig.-3: Left hemidiaphragm after repair of the injury.

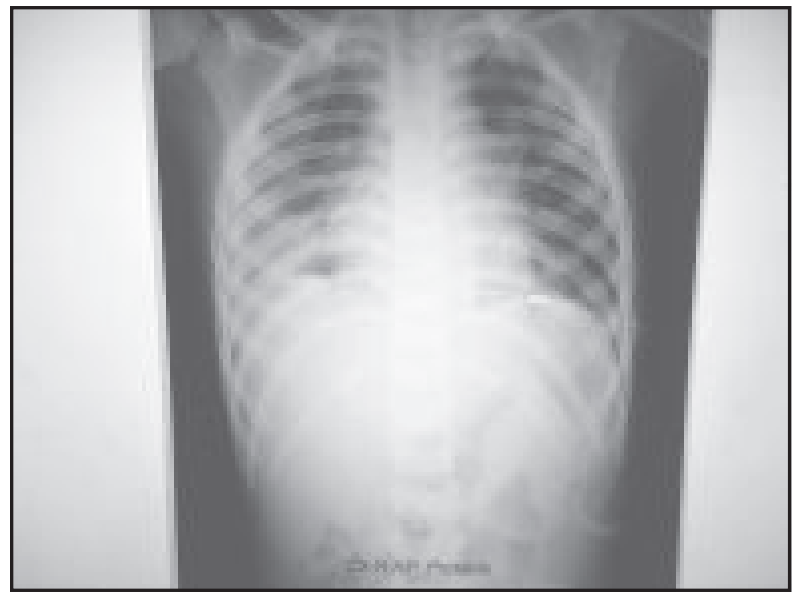

Fig.-4: Chest $X$-ray on first post operative day.

\section{Discussion}

Traumatic rupture of the diaphragm is uncommon in children due to the elasticity of their tissues ${ }^{10}$. Early detection and surgical repair of acute diphragmatic injury is vital for saving the life of symptomatic children ${ }^{5}$. Description of such injuries in children is rare in literatures ${ }^{11}$. Commonest mode of blunt diaphragmatic injury is the road traffic accident and in few patients fall from a height ${ }^{11}, 12$. In our case, landslide leads to compression over chest and abdomen. A 10 year study by Barsness and colleagues ${ }^{13}$ had shown that the mean age of affected children was 7 years with age range between 2-15 years. Our patient is a 8 years old boy who presented with severe respiratory distress, restlessness and pallor with surgical emphysema and absence of breathe sound on left side of the chest. Dyspnea is one of the main symptoms of patient having acute diaphragmatic rupture ${ }^{5}$. This finding directed us to a diagnosis of left sided hemopneumothorax and insertion of intercostal chest drain was unable to relieve the symptoms as it was found non functioning. Chest X-ray showed the drain tube in abdomen and on withdrawal eyes of the chest drain tube was found plugged with omentum. As physical examination is rarely helpful ${ }^{14}$, initially we also missed the diagnosis. On exploration, left sided diaphragmatic rupture was found involving both muscular and tendinous part extending from left crus of the diaphragm up to the anterior chest wall. Mobile hollow abdominal viscera with left lobe of the liver and spleen were found in the left thoracic cavity with the left lung collapsed. Shehaata and Shabaan also found that left sided diaphragmatic injury with avulsion of the costal origin of the diaphragm is more common in children. They found $50 \%$ of the patient had associated injuries as rib fracture, lung contusion and laceration, injury to liver and gut ${ }^{11}$. Soundapaan and associates had also found that left sided diaphragmatic injury was more common than the right and commonest site of rupture was at posterolateral aspect. They found associated injuries in $25 \%$ patients who succumbed to these injuries $^{12}$. In our case, the only associated injury was tear of the left costal margin. Abdominal viscera and the left lung were found intact. Immediate repair with interrupted or running nonabsorbable sutures is recommended ${ }^{15}$. We did in the same way and the post operative outcome was excellent.

\section{Conclusion}

Clinical diagnosis of rupture of the diaphragm after blunt thoracoabdominal trauma is often missed. Careful evaluation is needed keeping in mind about the possibility of such injury for correct diagnosis. Early intervention is essentially a life saving procedure in symptomatic children.

\section{References}

1. Koplewitz B Z, Ramos C T, Manson D E et al. Traumatic diaphragmatic injuries in infants and children: imaging findings. Pediatr Radiol 2000; 30, 471- 9.

2. Ramos C T, Koplewitz B Z, Babyn PS et al. What have we learned about traumatic diaphragmatic hernias in children? J Pediatr Surg 2000; 35, 601- 4 .

3. Rubikas R. Diaphragmatic injuries. Eur $\mathrm{J}$ Cardiothorac Surg 2001; 20(1), 53- 7. 
4. Smith $\mathrm{C} \mathrm{H}$, Novick $T \mathrm{~L}$, Jacobs $\mathrm{D} \mathrm{G}$ et al. Laparoscopic repair of a ruptured diaphragm secondary to blunt trauma. Surg Endosc 2000; 14(5), 501- 2.

5. Karnak I, Senocak M E, Tanyel F C et al. Diaphragmatic injuries in childhood. Surg Today 2001; 31(1), 5-11.

6. Russel RCG. The thorax. In: Russel RCG, William $\mathrm{N}$, Bulstrode CJK, editors. Short practice of surgery. London: Arnold; 2004. p. 847-74.

7. Stylianos S, Pearl R H. Abdominal trauma. In: Grosfeld J L, O' Neill J A, Coran A G, Fonkalsrud E W, editors. Pediatric Surgery. Philadelphia: Mosby; 2006. p.295-316.

8. Matthews B D, Bui $\mathrm{H}$, Harold $\mathrm{K} L$ et al. Laparoscopic repair of traumatic diaphragmatic. Surg Endosc 2003; 17, 254.

9. Pross M, Manger T, Mirow L et al. Laparoscopic management of late diagnosed major diaphragmatic rupture. J Laparoendosc Adv Surg Tech 2003; 10, 111.
10. Khan T R, Rawat J, Maletha M et al. Traumatic diaphragmatic injuries in children: do they really mark the severity of injury? Our experience. Pediatr Surg Int 2009; 25(7), 595-9.

11. Shehata S M, Shabaan B S. Diaphragmatic injuries in children after blunt abdominal trauma. J Pediatr Surg 2006; 41(10), 1727-31.

12. Soundappan S V S, Holland A J A, Cass D T et al. Blunt traumatic diaphragmatic injuries in children. Injury 2005; 36(1), 51-4.

13. Barsness K A, Bensard D D, Ciesla D et al. Blunt diaphragmatic rupture in children. J Trauma 2004; 56(1), 80-2.

14. Wesson D E. Thoracic injuries. In: Grosfeld J L, O' Neill J A, Coran A G, Fonkalsrud E W, editors. Pediatric Surgery. Philadelphia: Mosby; 2006. p.275-294.

15. Hemmila $M R, W a h l W L$.Management of the injured patient. In:Way LW, Doherty GM, editors. Current surgical diagnosis and treatment.New York: Lange Medical books; 2006.pp.207-244. 